\title{
Stability of chemical available fluoride in Chilean toothpastes
}

Constanza E. Fernández, DDS, PhD ${ }^{1,2^{*}}$; Carola A. Carrera, DDS, $\mathrm{PhD}^{3^{*}}$; Cecilia Muñoz-Sandoval, DDS ${ }^{4}$; Jaime A. Cury DDS, MSc, PhD ${ }^{1}$; Rodrigo A.

Giacaman, DDS, PhD ${ }^{4,5}$

1. Piracicaba Dental School, UNICAMP, Piracicaba, SP, Brazil.

2. Department of Epidemiology, School of Public Health, University of Michigan, Ann Arbor, USA.

3. University of Minnesota, Minneapolis, MN, USA.

4. Cariology Unit, Department of Oral Rehabilitation, University of Talca, Talca, Chile.

5. Interdisciplinary Excellence Research Program on Healthy Aging (PIEI-ES), University of Talca, Talca, Chile.

* Both authors contributed equally to this work.

Short title: Fluoride stability in Chilean toothpastes

\section{Acknow ledgements}

We thank to Manuel Zura and Waldomiro Vieira-Filho for their technical assistance in the analyses of the toothpastes.

Authors report no conflict of interest. J.A. Cury has acted occasionally as consultant for Colgate/Palmolive in Brazil and for the Brazilian Ministry of Health during the time that this study was conducted.

This is the author manuscript accepted for publication and has undergone full peer review but has not been through the copyediting, typesetting, pagination and proofreading process, which may lead to differences between this version and the Version of Record. Please cite this article as doi: 10.1111/ipd.12288

This article is protected by copyright. All rights reserved 


\section{Statement of author contributions}

RAG and JAC conceived the research idea. CF, CAC and CM designed the experiments. CF performed the experiments. $C F, C A C$ and $C M$ analyzed the data. CAC wrote the first draft. CF and RAG revised and finished the manuscript. All the authors approved the submitted final version of the manuscript.

\section{Corresponding author:}

Rodrigo A. Giacaman, DDS, PhD, Associate Professor

Escuela de Odontología, Universidad de Talca

2 Norte 685, Talca (Chile)

Tel. + 56712201546

e-mail giacaman@utalca.cl

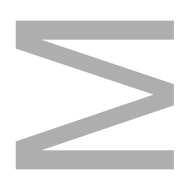

Word count: 4871

Tables: 1

Figures: 1

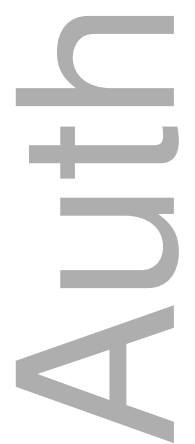

This article is protected by copyright. All rights reserved 
Received Date : 27-Sep-2016

Revised Date : 22-Nov-2016

Accepted Date : 17-Dec-2016

Article type : Original Article

Stability of chemically-available fluoride in Chilean toothpastes (1)

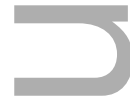

Summary

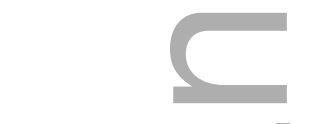

Objectives. To

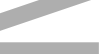

compare

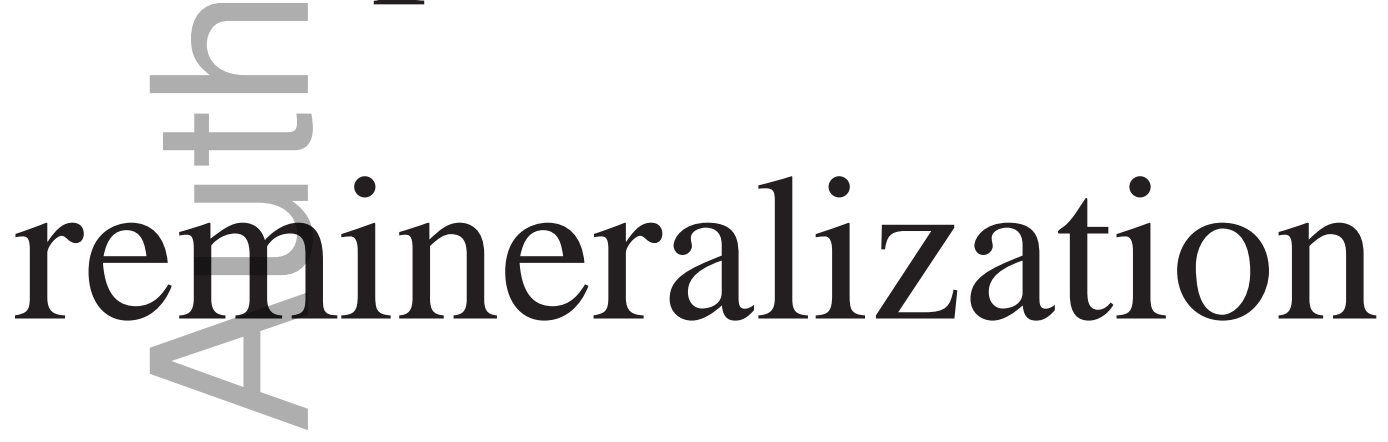

potential 


\section{of topical fluoride}

varnishes with

added calcium
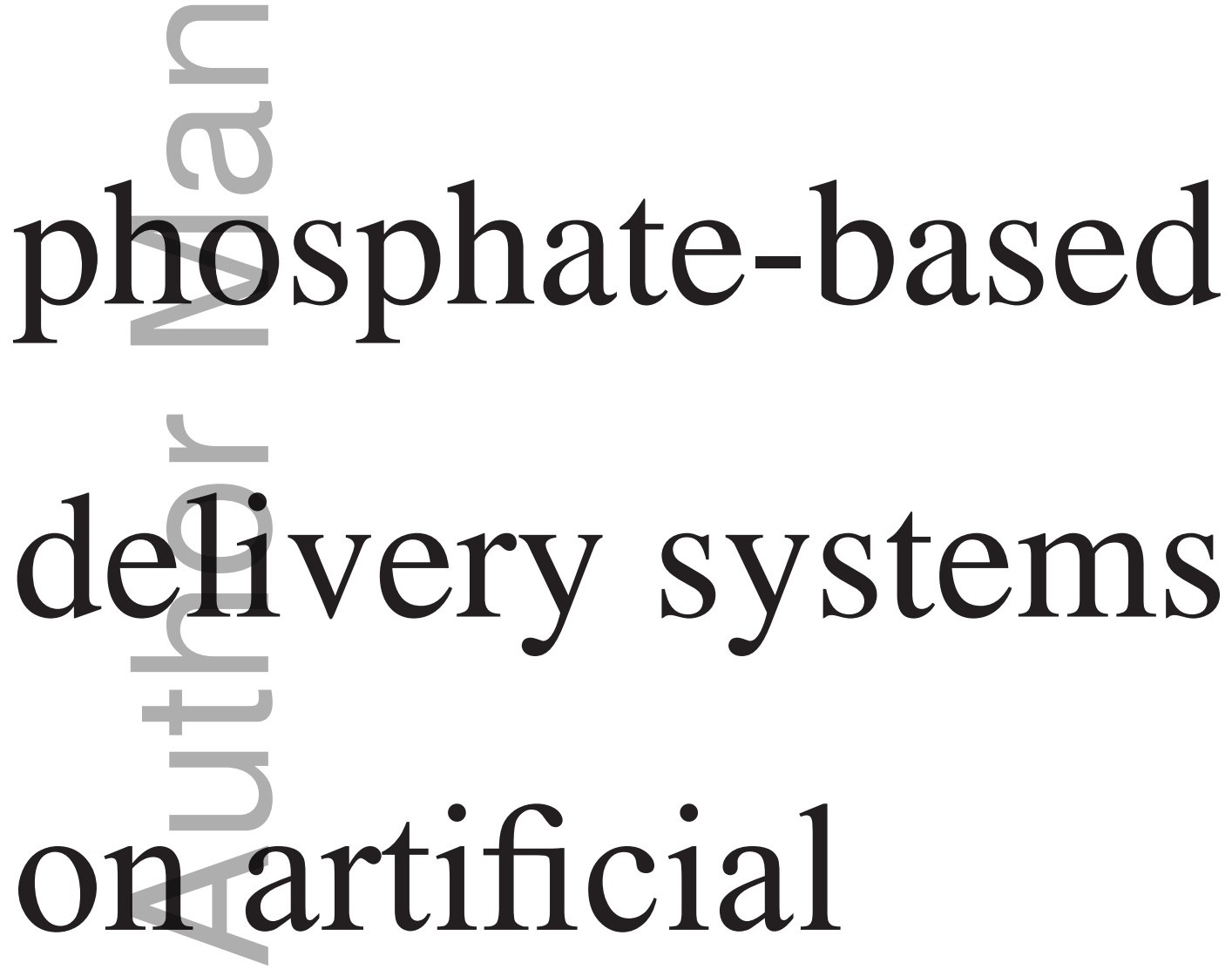

This article is protected by copyright. All rights reserved 


\section{enamel caries.}
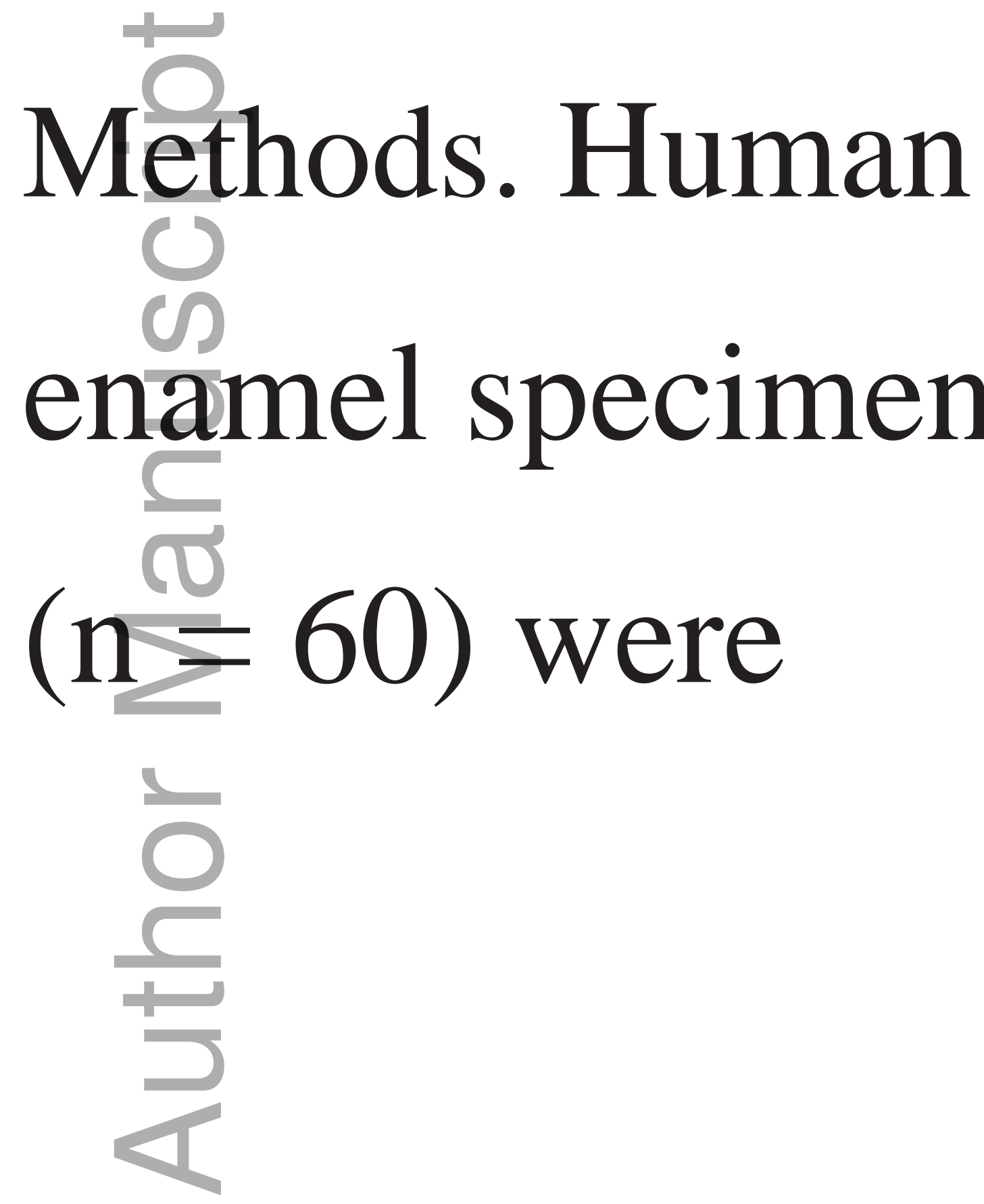

This article is protected by copyright. All rights reserved 
randomly divided

into six groups:

Group 0: Control

(no varnish), Group

1: Duraphat

â

, Group 2: MI 


\section{Varnish}
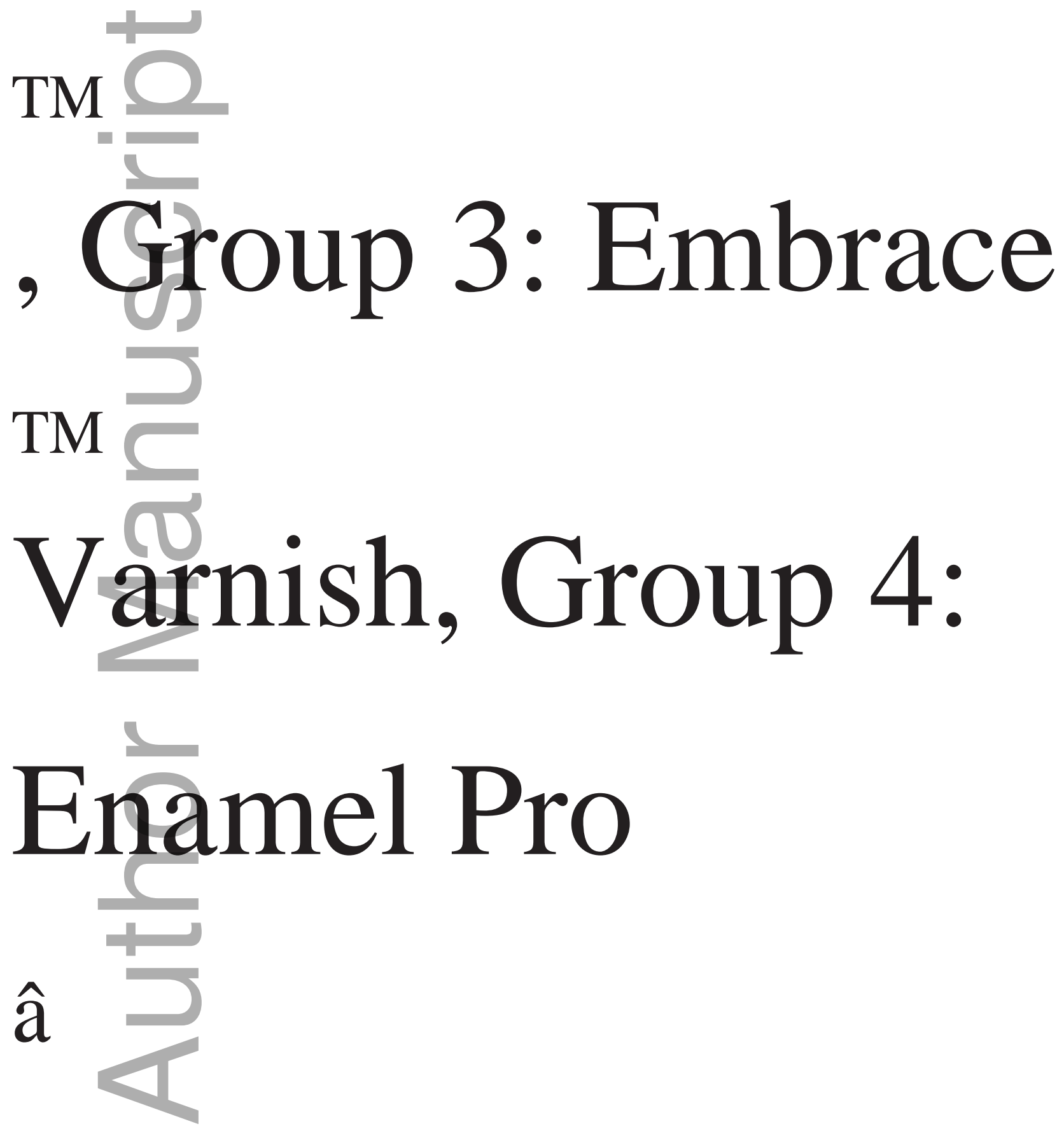


\section{Varnish, and Group}
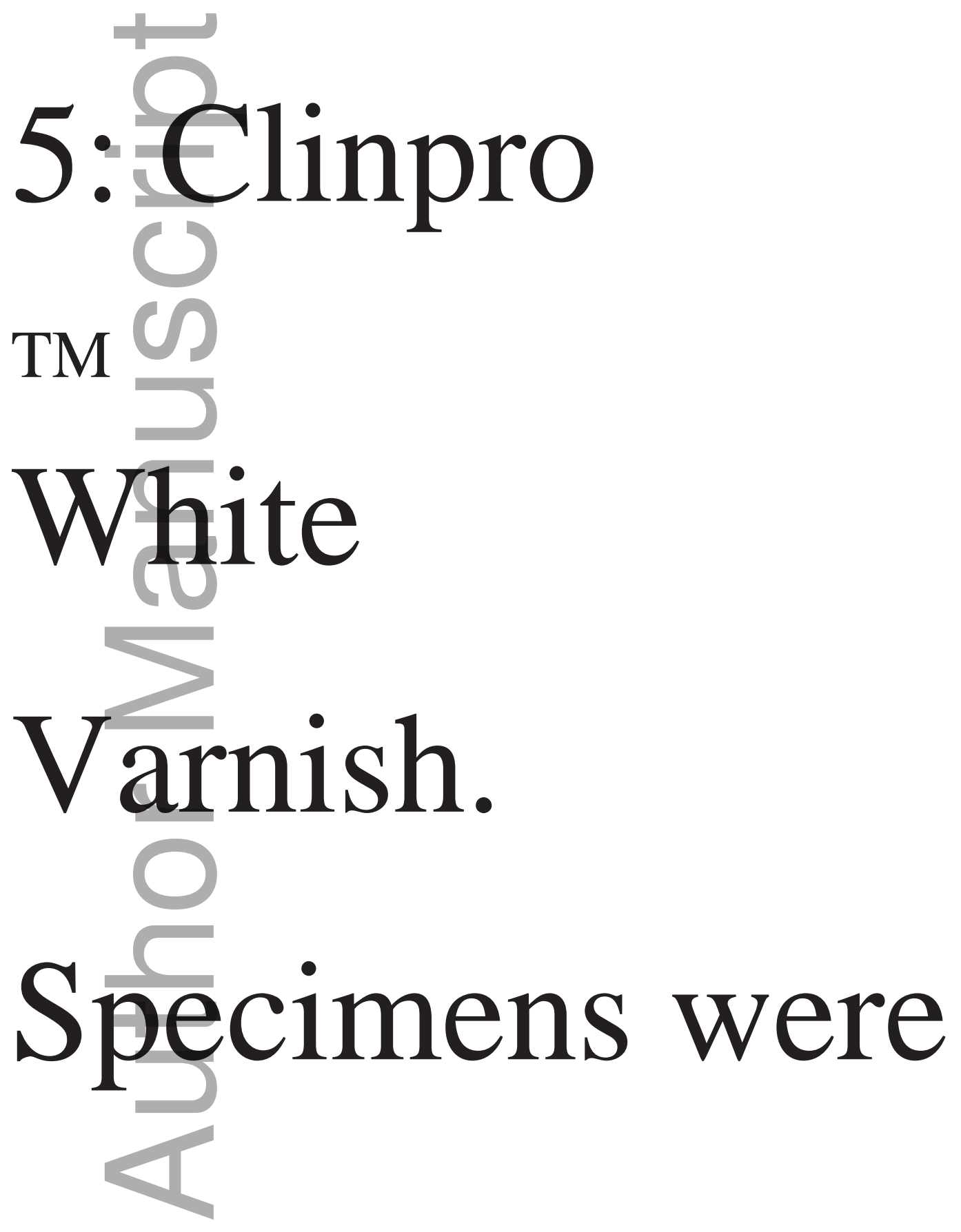


\section{immersed in}
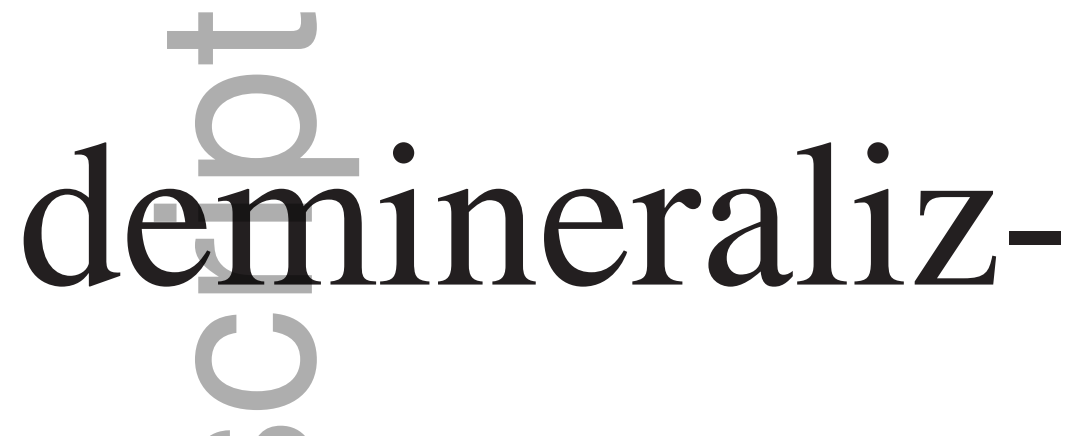

-

ing solution for 96

$h$ to create artificial

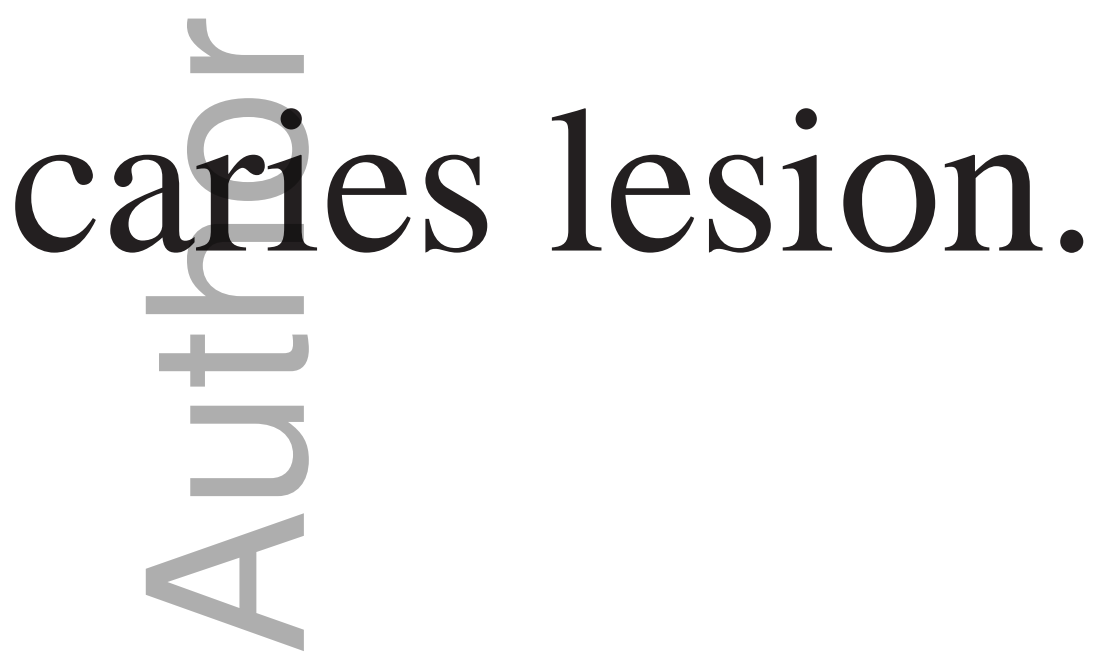


Each specimen was then immersed in

artificial sal-
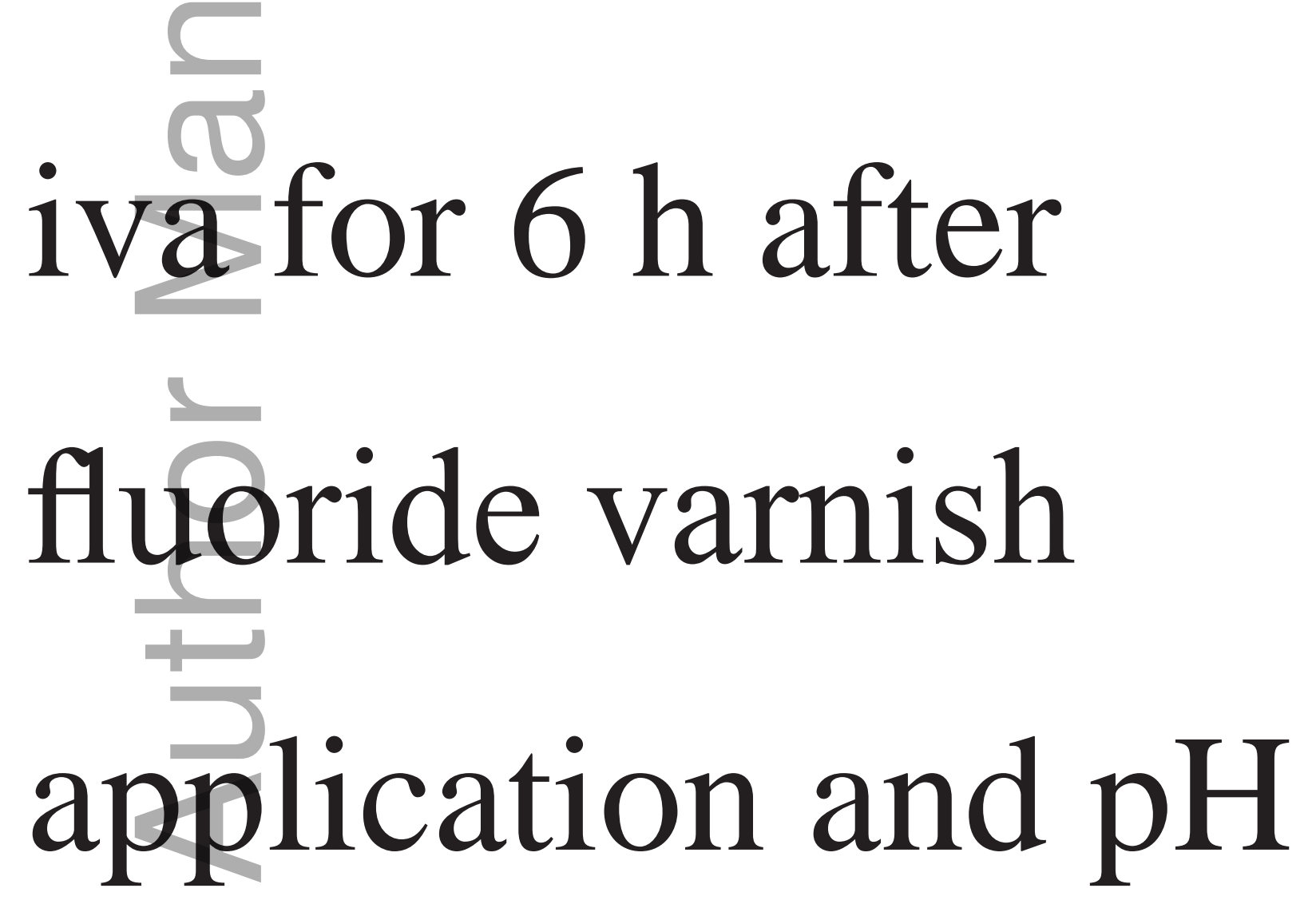

This article is protected by copyright. All rights reserved 
cycling was

performed for 8

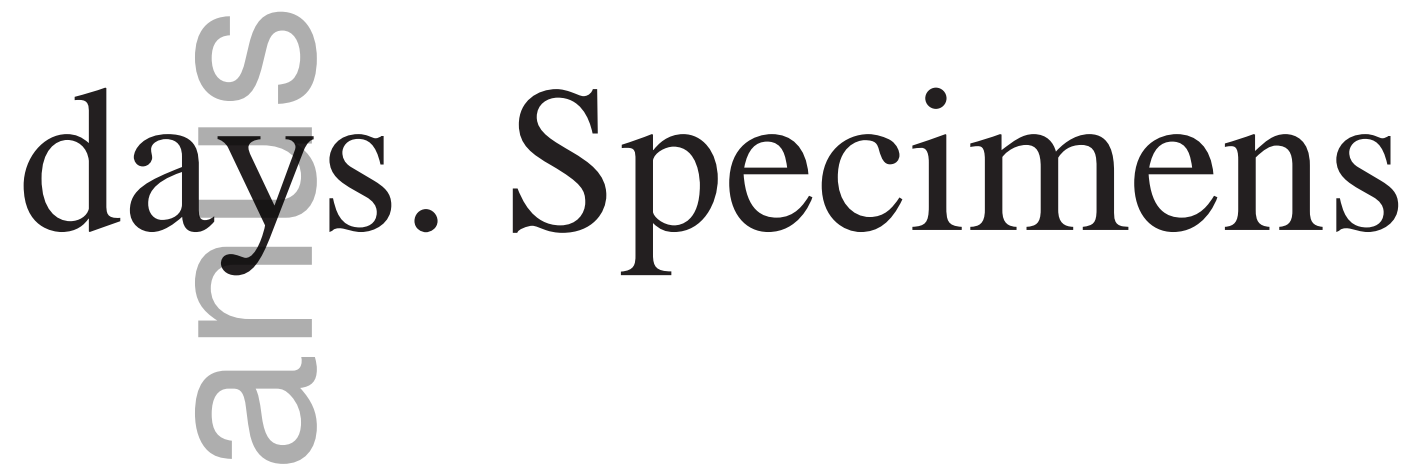

were

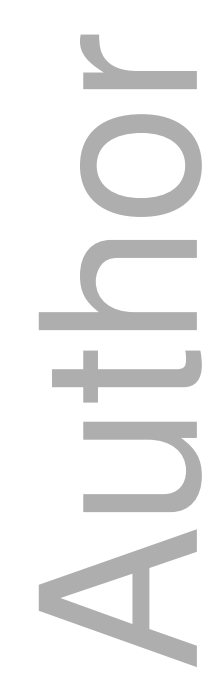

This article is protected by copyright. All rights reserved 


\section{evaluated using}

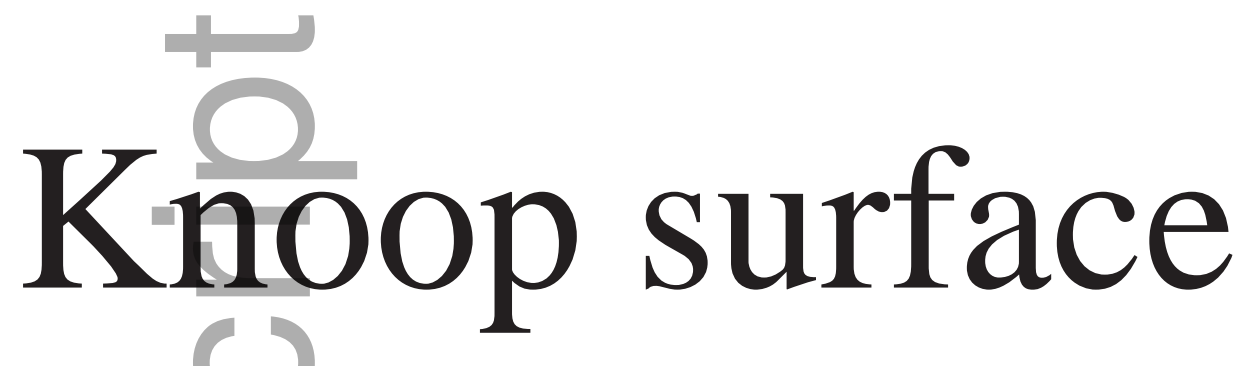

microhardness
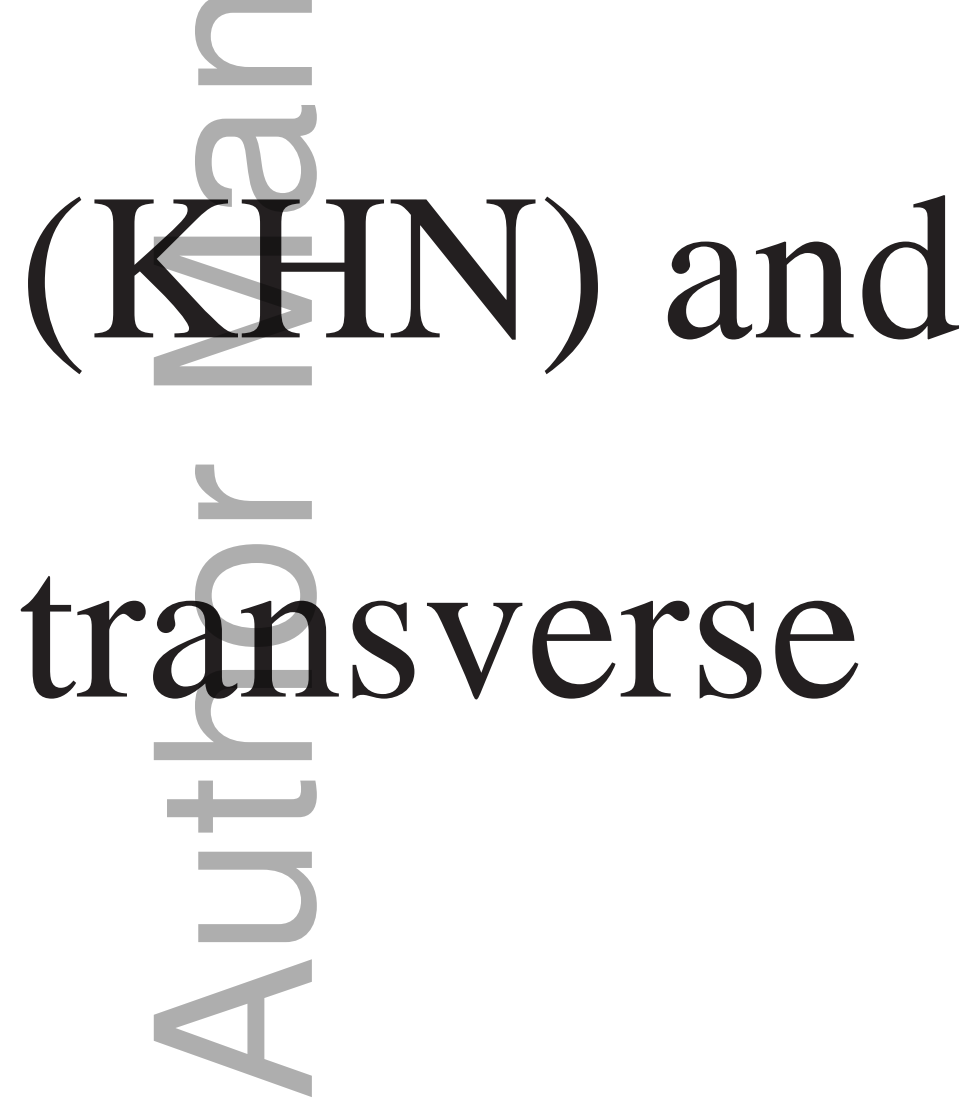

This article is protected by copyright. All rights reserved 


\section{microradiography}

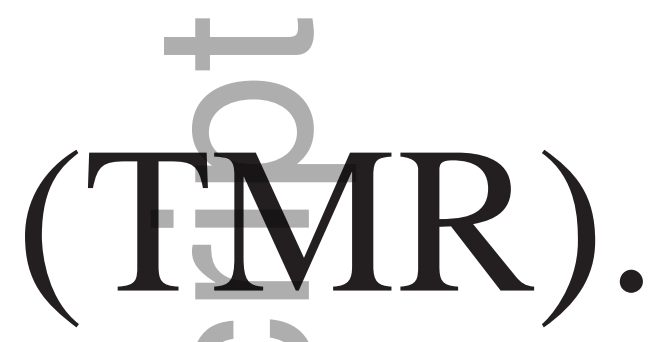

()

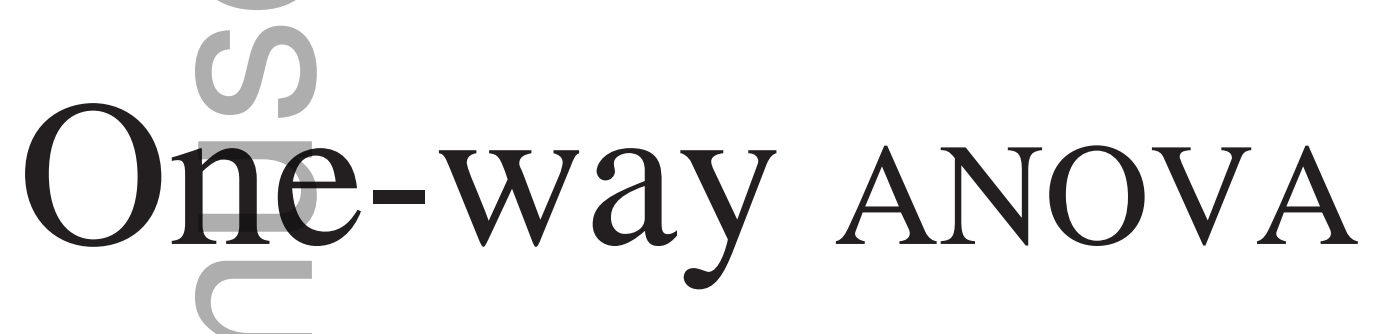

test was performed

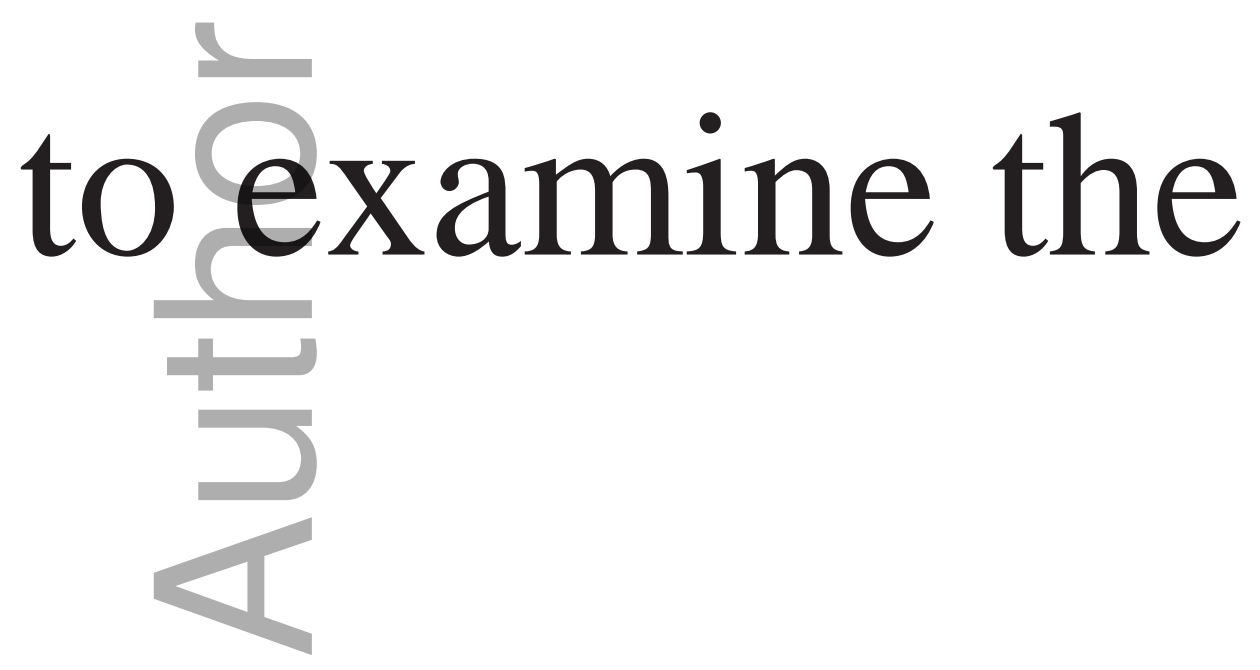




\section{effect of fluoride}

varnishes on
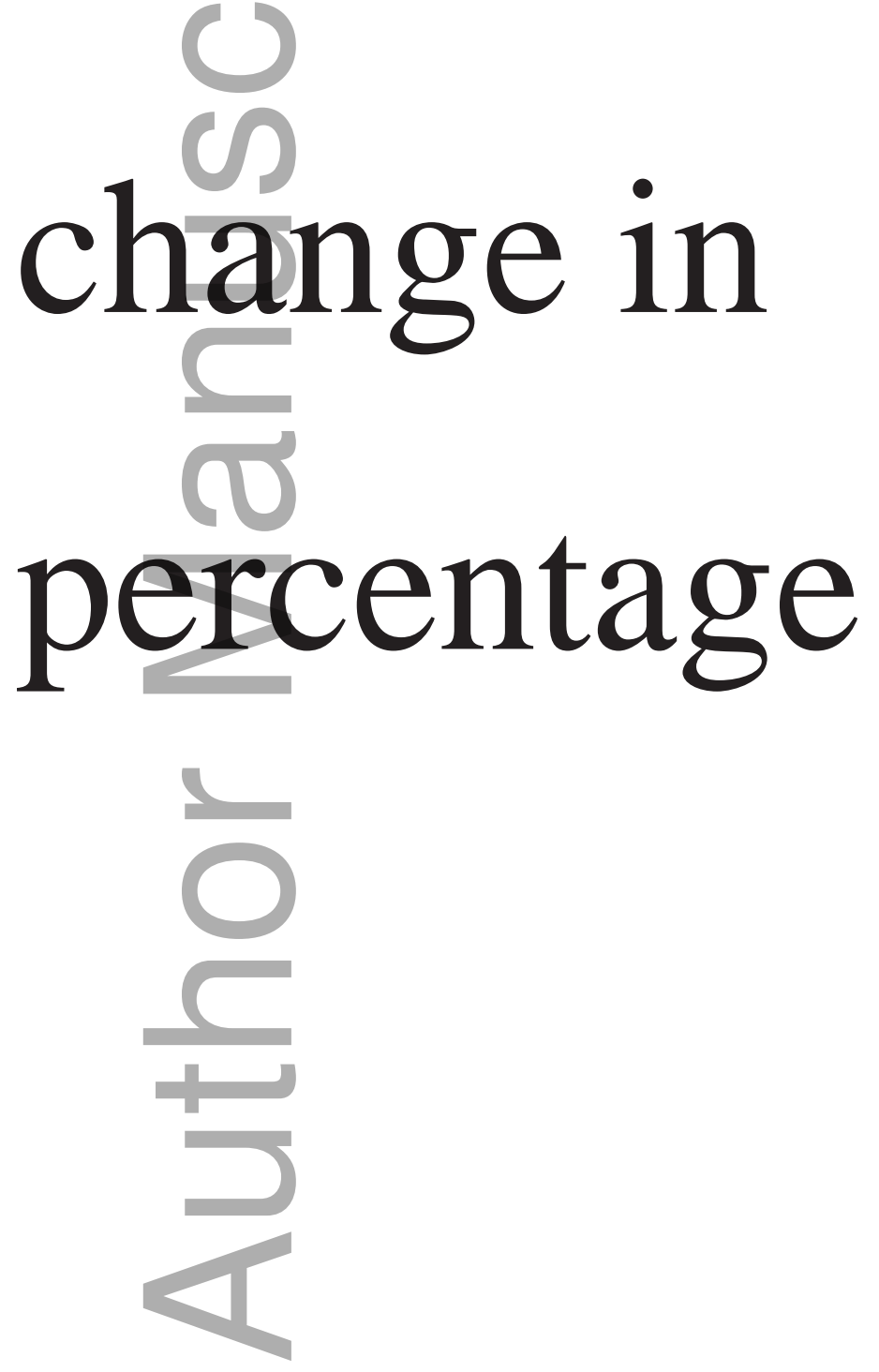

This article is protected by copyright. All rights reserved 


\section{of surface hardness}
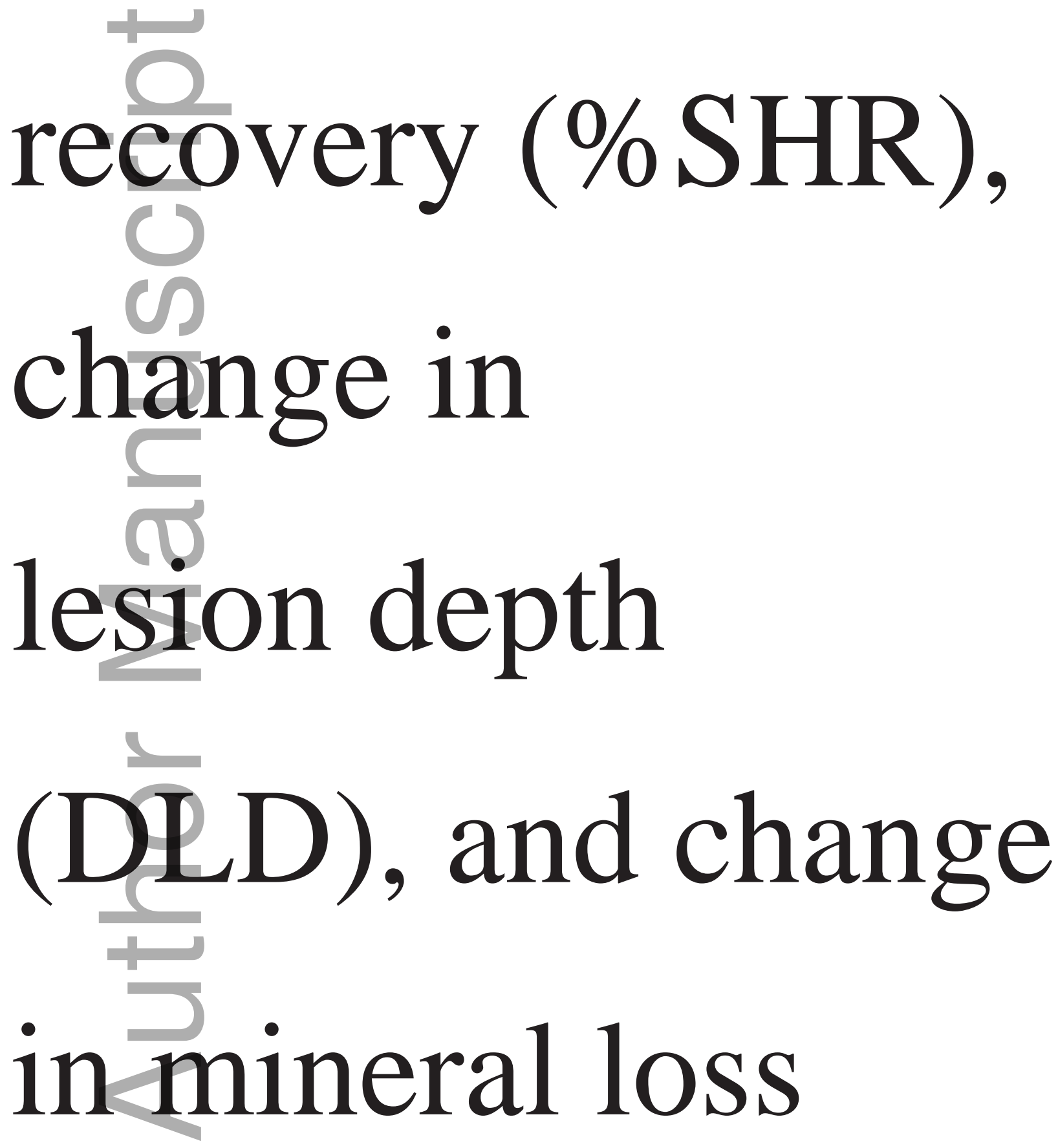
(DDZ) with the

significance limit

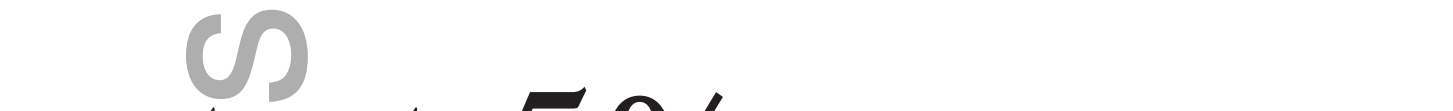

setat $5 \%$.

Results. \%SHR of

enămel following

r

treatment

This article is protected by copyright. All rights reserved 
with Group 1 was sigñificantly higher<smiles></smiles>

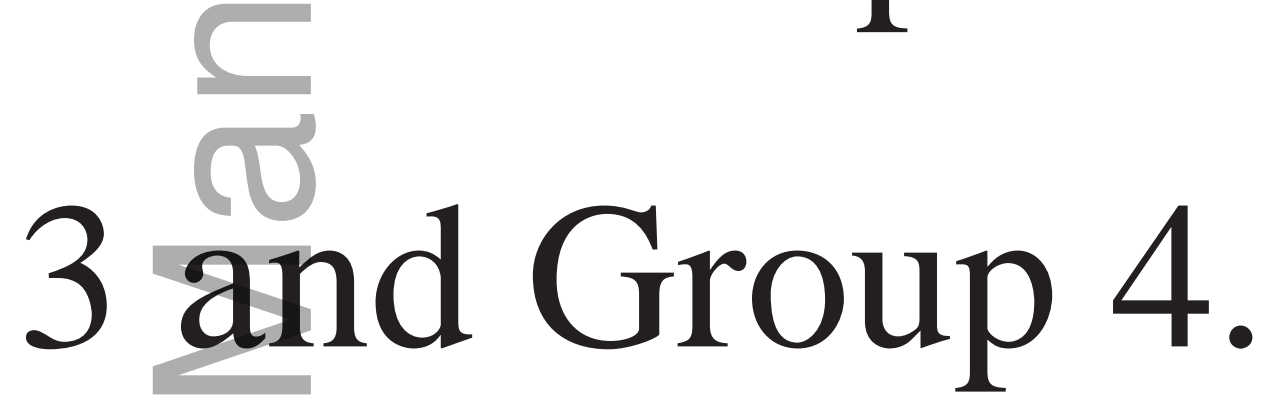

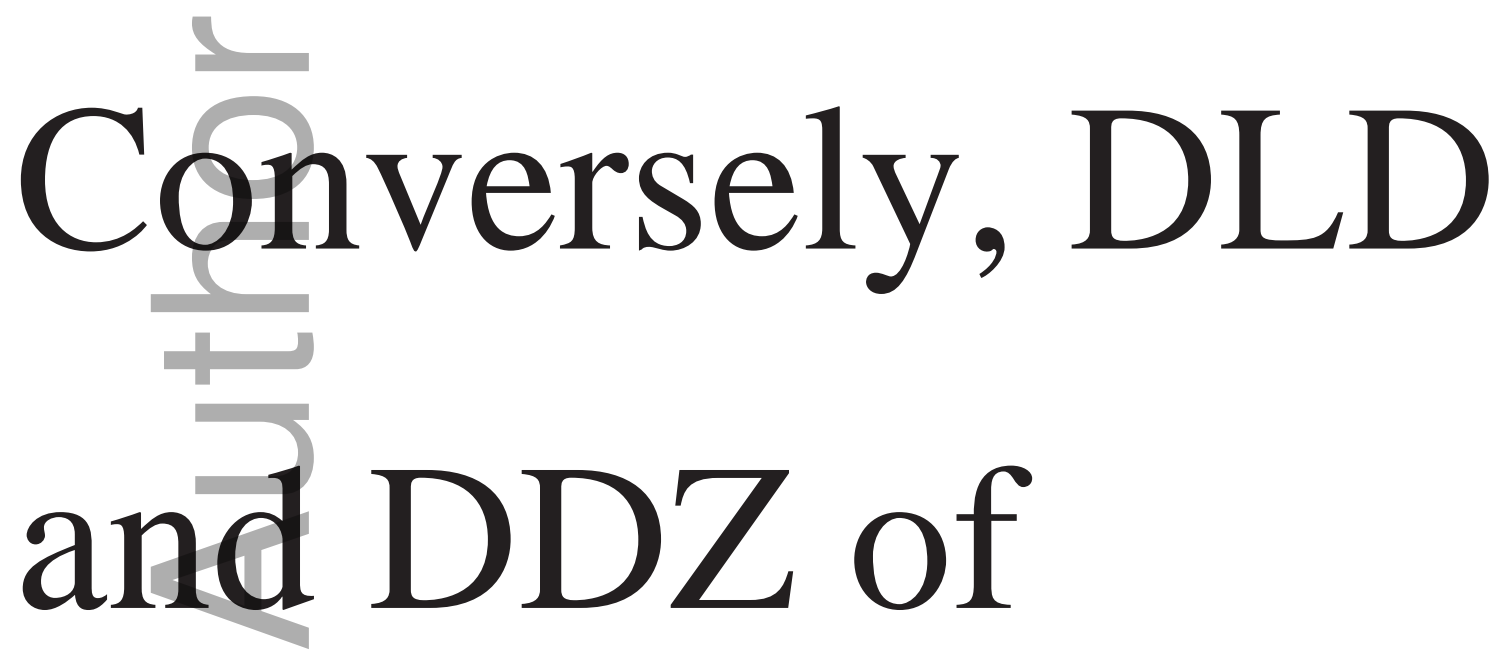


Group 1 were

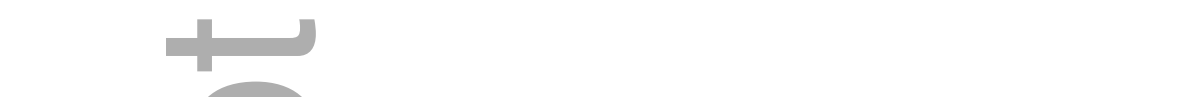

significantly higher

thạ Group 2,

Group 3, and

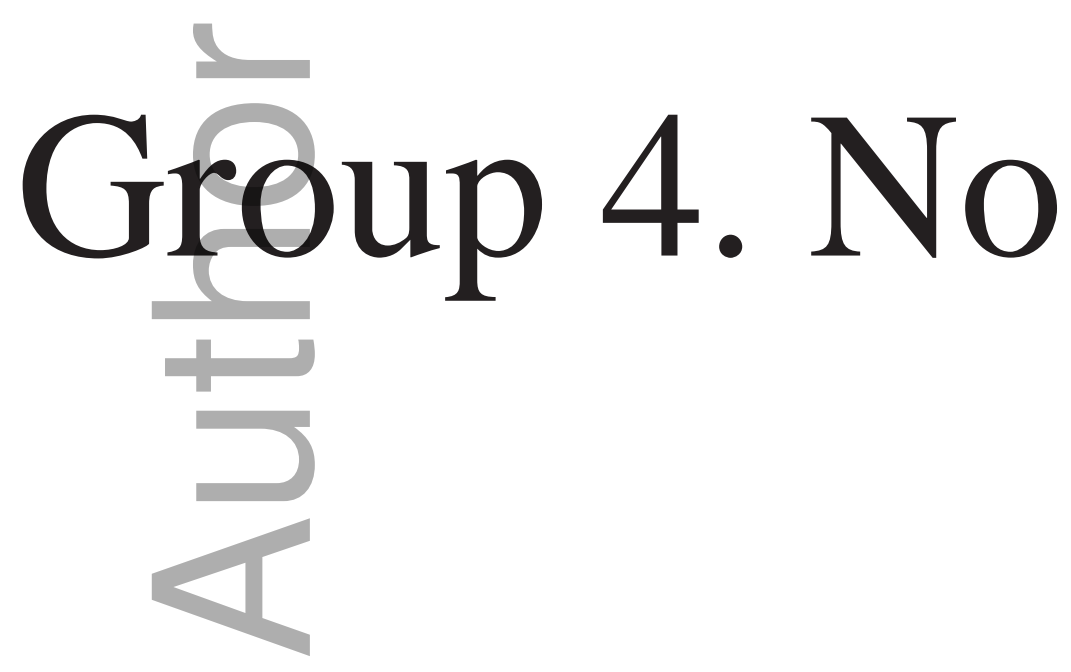

This article is protected by copyright. All rights reserved 


\section{significant}
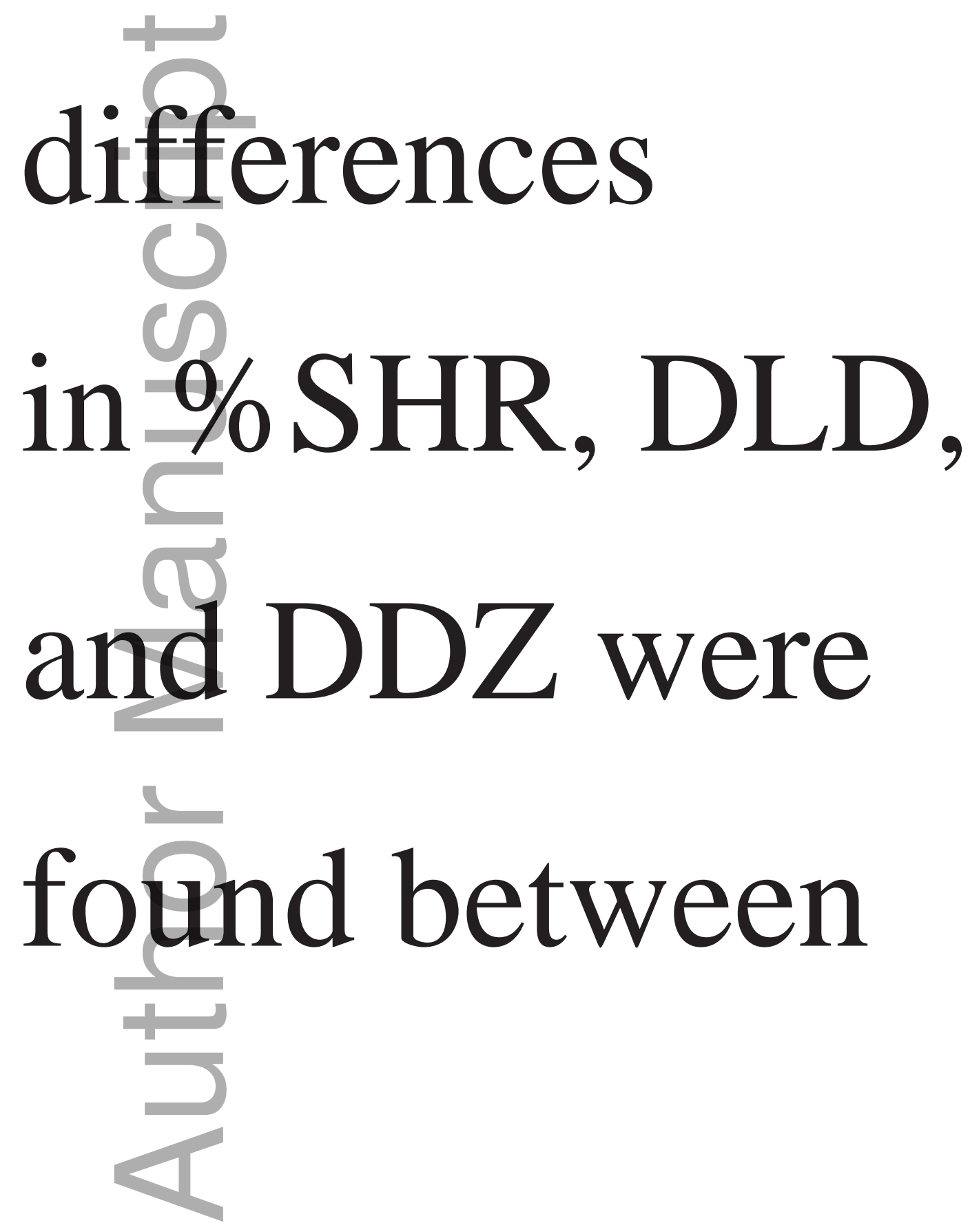

This article is protected by copyright. All rights reserved 


\section{Group 1 and Group}
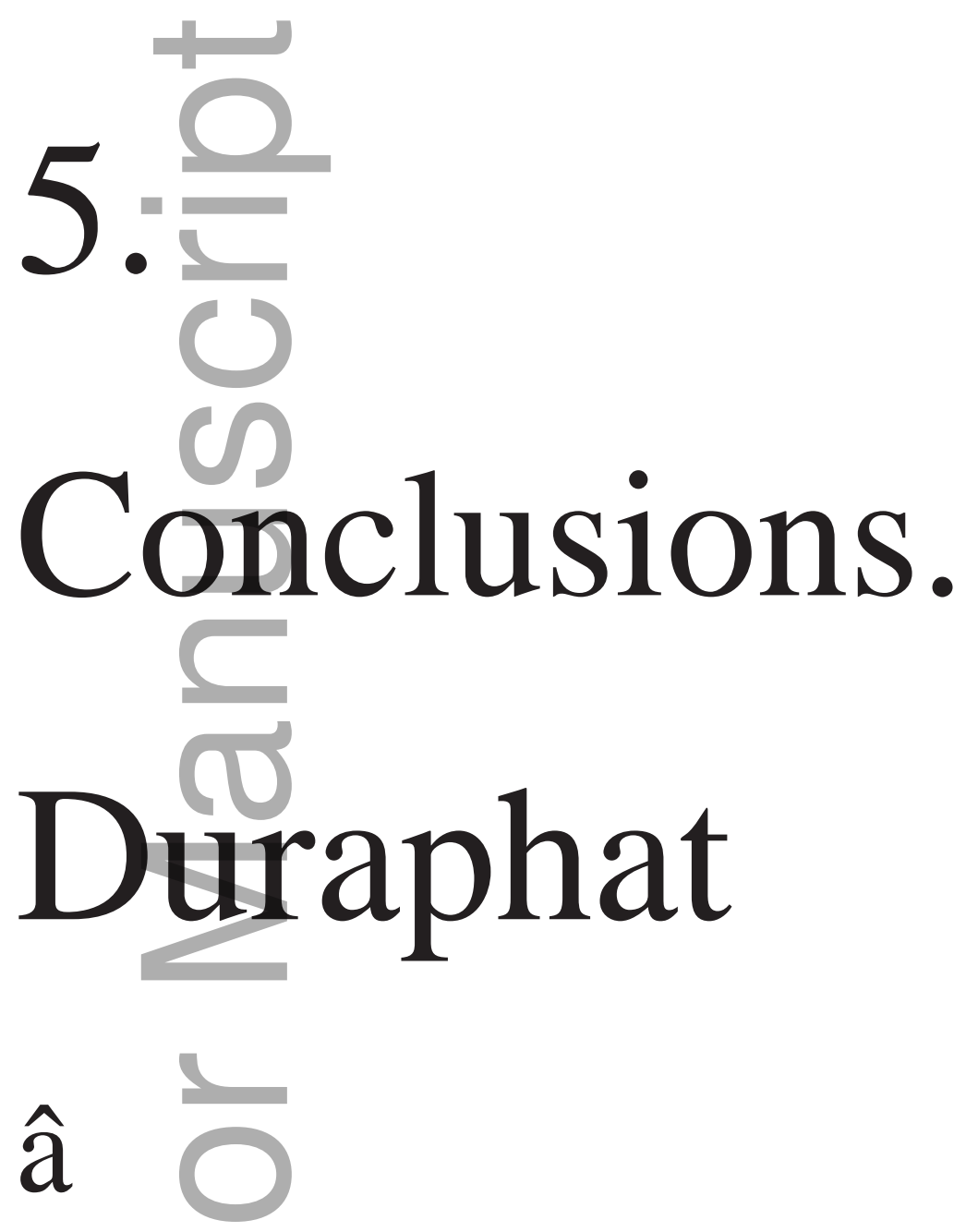

alöne achieves

significant 
remineralization of

enamel carious
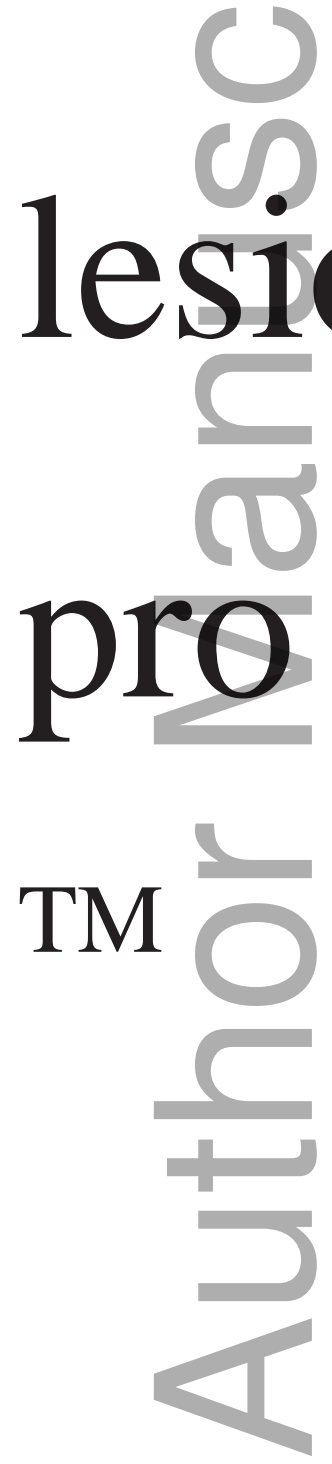

This article is protected by copyright. All rights reserved 
White Varnish had

similar enamel

reminer-

alization effect as

Düraphat

â 
Background. Storage time may reduce the amount of soluble fluoride (F) in toothpastes. Although we previously studied the type and concentration of $F$ in fresh samples of commercial Chilean toothpastes, their stability was not determined. Aim. To evaluate the stability of soluble $\mathrm{F}$ in Chilean toothpastes after one year of storage. Design. All the toothpastes $(n=30)$ previously used were re-analyzed after one year of storage time at room temperature $\left( \pm 22^{\circ} \mathrm{C}\right)$. Total $F(T F=$ soluble $F+$ insoluble $F$ ) and the total soluble $\mathrm{F}$ (TSF=F ion + MFP ion) were assessed using an ion-specific electrode, through a validated methodology. Data were expressed in ppm of $\mathrm{F}$ ( $\mathrm{mg}$ $\mathrm{F} / \mathrm{kg}$ ). Results. Mean ( $\pm S D ; n=30)$ TF and TSF concentrations after storage were $1,049 \pm 427$ and $987 \pm 411$ ppm F, respectively. Five toothpastes showed between $30 \%$ to $50 \%$ of insoluble F, 4 of them formulated with MFP/calcium-based abrasive. In 2 products, there was a reduction of TSF below the evidence-based anticaries effectiveness threshold of $1,000 \mathrm{ppm}$ F. Conclusions. Although most of the toothpastes tested kept their original TSF content after one year of storage, some products evidenced an important reduction, which may compromise their anticaries efficacy. Reductions in TSF may be explained by an incorrect $F$ salt-abrasive formulation.

Keywords: Fluoride; Dentifrices; Sodium fluoride; Monofluorphosphate; Calcium carbonate; Dental caries; Soluble fluoride.

\section{Introduction}

Caries decline observed in various countries coincides with the introduction of fluoridated $(F)$ toothpastes ${ }^{1-3}$, which is considered the most reasonable method to deliver fluoride ${ }^{4,5}$. Although regular toothbrushing with $F$ toothpastes is crucial in aiding caries prevention measures ${ }^{6,7}$, to achieve evidence-based effectiveness in both the primary ${ }^{8}$ and permanent dentitions ${ }^{9,10}$, toothpastes should contain at least 1,000 ppm F. Conventional dentifrices with $F$ concentrations between 1,000 and 1,500 ppm $\mathrm{F}$ may be used at all ages, being careful to use small amounts $(0.1-0.3 \mathrm{~g})$ in children $^{5,11}$. Moreover, the caries-preventive effect of $F$ toothpastes seems to be independent of the type of $F$ salt used, i.e. sodium fluoride (NaF) or monofluorphophate (MFP) ${ }^{6,9}$.

This article is protected by copyright. All rights reserved 
The caries preventive effect of toothpastes is related with the $\mathrm{F}$ bioavailability, which is directly associated with the amount of total soluble $F(T S F)^{5,12}$. The soluble $F$ fraction is the active compound involved in reducing demineralization and enhancing remineralization ${ }^{13-16}$. Hence, the anti-caries potential of $F$ dentifrices can be compromised if the $F$ ion is not chemically available or soluble. Lack of availability of soluble $\mathrm{F}$ in toothpastes may derive from an inadequate formulation and/or loss of stability ${ }^{14,17}$. Chemical stability of TSF incorporated in the original formulation is greatly influenced by the type of abrasive and its compatibility with the fluoridated agent. TSF can be present as ionic free (e.g. $\mathrm{F}$ in NaF) or in its ionizable form (e.g. $\mathrm{FPO}_{3}{ }^{2-}$ in $\mathrm{NaFPO}_{3}$ (MFP)). The ineffective insoluble $\mathrm{F}$ (InF) fraction can be generated when calcium-based abrasives react with the $F$ contained in the tube, forming calcium fluoride $\left(\mathrm{CaF}_{2}\right)$ and decreasing $\mathrm{TSF}^{14}$. To avoid this undesired reaction, NaFcontaining toothpastes are commonly formulated with inert compounds, such as silica-based abrasives. Conversely, toothpastes formulated with calcium-based abrasives must use MFP as the source of $F$, because the covalent bond between $F$ and phosphate avoids an immediate reaction between $\mathrm{F}$ and calcium $\left(\mathrm{Ca}^{++}\right)^{14,18}$. Although the simultaneous presence of $\mathrm{Ca}^{++}$and MFP in a dentifrice should be stable over time, it is possible that MFP undergoes hydrolysis within the tube during storage, releasing $\mathrm{F}$ ions to form inactive $\mathrm{CaF}_{2}{ }^{5,19}$. Hence, monitoring TSF content in commercial dentifrices becomes needed to guarantee anti-caries activity of toothpastes at all times.

We previously investigated the $F$ content and the formulation of several toothpastes sold in Chile intended for children ${ }^{20}$ and for the general population ${ }^{21}$. Most toothpastes were formulated either with $\mathrm{NaF}$ ( $70 \%$ of samples) or MFP ( $30 \%$ of samples) as their source of $F$. Our results showed that most toothpastes had concentrations of TSF that closely matched their content of total F (TF). The stability of TSF in those toothpastes, however, has never been tested and no information is available. Given the importance of maintaining optimal concentrations of $F$ in a toothpaste to achieve the expected anti-caries effect and some evidence showing reduction of TSF after storage ${ }^{18}$, the aim of the present study was to evaluate the stability of TSF contained in dentifrices commercially available in Chile after one year of storage time.

This article is protected by copyright. All rights reserved 


\section{Materials and Methods}

Toothpastes tested. Samples were obtained from the three main chain drugstores in Chile. A total of thirty toothpastes were found belonging to fourteen brands. Only toothpastes that were simultaneously available at the three drugstores were purchased. Thus, toothpastes intended for children $(n=12)^{20}$ and for the general public $(n=18)^{21}$ were purchased in triplicate, one tube from each store. Toothpastes were coded to allow blind analysis. At baseline, all the products were analyzed for $F$ availability after the toothpastes were purchased and the results were published ${ }^{20,21}$. After the initial analysis, toothpastes were maintained in a box and stored in laboratory facilities for one year at room temperature $\left( \pm 22^{\circ} \mathrm{C}\right)$, simulating shelf conditions in a store or at home. After storage, toothpastes were analyzed again to assess the content of the different $F$ fractions.

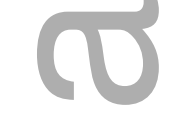

Fluoride preparation. Measurements of TSF, which represents the $\mathrm{F}$ available as ion $\mathrm{F}$ - and/or ion MFP $\left(\mathrm{FPO}_{3}{ }^{2-}\right.$ ), and TF that corresponds to the sum of TSF and InF, were carried out. All the analyses were made in duplicates according to a vastly used protocol $^{18,22,23}$. Briefly, toothpastes were weighed $(100 \pm 10 \mathrm{mg}$ ) and homogenized in $10.0 \mathrm{~mL}$ of deionized water. TF was obtained by mixing $0.25 \mathrm{~mL}$ of the suspension with $0.25 \mathrm{~mL}$ of $2 \mathrm{M} \mathrm{HCl}$ and kept during $1 \mathrm{~h}$ at $45^{\circ} \mathrm{C}$ to induce MFP ion breakdown into $\mathrm{F}$ ion and to dissolve InF bound to the abrasive. The mixture was neutralized using $0.5 \mathrm{~mL} 1 \mathrm{M} \mathrm{NaOH}$ and buffered with $1 \mathrm{~mL}$ TISAB II ( $1 \mathrm{M}$ acetate buffer, pH 5.0, containing $1 \mathrm{M} \mathrm{NaCl}$ and $0.4 \%$ CDTA (cyclo- hexylenedinitrilo tetraacetic acid)). To obtain TSF, the toothpaste suspension was centrifuged (10 $\mathrm{min}$ at 3,000 $\mathrm{g}$ ) at room temperature to remove InF and to obtain a supernatant for the next analyses. An aliquot of $0.25 \mathrm{~mL}$ of the supernatant was mixed following the same abovementioned procedures.

F assessment. A F electrode (Orion model 96-09, Orion Research, Cambridge, MA, USA) coupled to an ion analyzer (Orion EA-740, Orion Research, Cambridge, MA, USA) was used to determine F concentration of TF and TSF fractions. To perform the This article is protected by copyright. All rights reserved 
measurements, F electrode was first calibrated using F standards containing 0.06 to $8.0 \mathrm{ppm} \mathrm{F}$. Standards were prepared with the same reagents used to analyze the samples. A linear regression equation was obtained from the standards $\left(r^{2}>0.999\right)$, so units from the measurements $(\mathrm{mV})$ could be converted to $F$ concentrations expressed as ppm F ( $\mu \mathrm{g} \mathrm{F/g}$ toothpaste). The concentration of InF was obtained subtracting TSF from TF and its percentage calculated by the formula \%InF = $(\mathrm{InF}) /(\mathrm{TF}) 100$. Mean concentration of $\mathrm{F}$ and the standard deviation (SD) were calculated for each toothpaste using Excel spreadsheet (Microsoft) and results were presented in comparison with those previously obtained with the fresh samples.

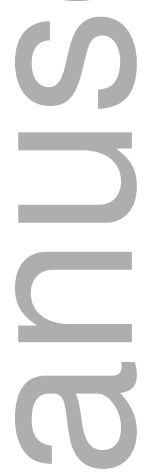

\section{Results}

Table 1 shows the results for TF and TSF after 1 year of storage (aged samples) and their respective baseline values evaluated immediately after purchase (fresh samples) ${ }^{20,21}$. The concentration of InF for each condition (fresh and ages samples) is shown in Figure 1. In the aged toothpastes, TF content ranged between 1554 7.8 to $277 \pm 212 \mathrm{ppm} F$, which are relatively close to the TF concentration declared in the labels ( 1,450 to $422 \mathrm{ppm}$ F). Product \#27 was the exception, as it displayed a TF concentration three times higher than the $\mathrm{F}$ concentration declared in the label. In general, TF concentration remained stable after one year of storage. Conversely, TSF had relevant fluctuations across the aged samples. Indeed, TSF content in these products ranged between $1474.6 \pm 34.2$ and $229.7 \pm 3.2 \mathrm{ppm}$ F. An accentuated variation from fresh to aged occurred in toothpastes \#4, \#16, \#27, \#28 and \#30, that showed a decrease in TSF content and consequently an increment in InF (Figure $1)$.

Toothpaste \#4, formulated with MFP, displayed the most dramatic decrease in TSF, from $958.8 \pm 82$ to $630 \pm 63.3 \mathrm{ppm}$ of $\mathrm{F}$ (Table 1), which corresponds to $29 \%$ of InF in the fresh condition and $52 \%$ InF in the aged condition (Figure 1). Toothpastes \#16 This article is protected by copyright. All rights reserved 
formulated with MFP and \#27 made with $\mathrm{NaF}$, showed an increase in the $\% \mathrm{InF}$ from $26 \%$ to $31 \%$ and from $28 \%$ to $37 \%$, respectively. Despite the decrease, TSF in those

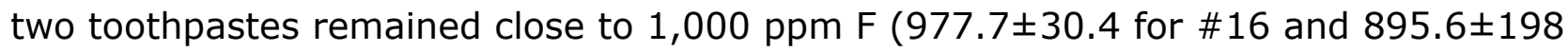
for \#27). Toothpastes \#28 and \#30, both containing MFP as the source of F, are low $\mathrm{F}$ concentration toothpastes and had an increase of InF after storage from $28 \%$ to $46 \%$ and from $30 \%$ to $53 \%$, respectively. TSF content in those toothpastes was very

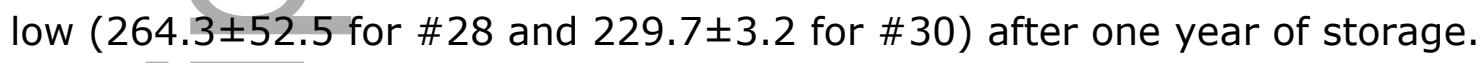

\section{Discussion}

To achieve the desired caries-preventive effect, fluoridated toothpastes must contain soluble $\mathrm{F}$ in enough quantities ${ }^{5}$. The importance of determining $\mathrm{F}$ concentrations in toothpastes and its stability over time as quality control has been being highlighted ${ }^{18,24-26}$. Since toothpastes are maintained in the store or at home for variable times, it is important to ensure that they contain enough TSF until the toothpaste is purchased and used. In this study, we evaluated the stability of TSF content after one year of storage under normal shelf or home conditions. Most of the toothpastes marketed in Chile were included in this evaluation. In a previous publication ${ }^{20}$, we had reported and discussed that the Chilean regulation was not in consistency with the best available evidence. After several discussions and analyses along with the dental health authority, the regulation for $F$ toothpastes sold in Chile was recently modified ${ }^{27}$. These guidelines currently recommend that toothpastes intended for children of any age should contain $F$ concentrations between 1,000 and 1,500 ppm $F$ (conventional $F$ concentration) ${ }^{27}$. The old Chilean regulation ${ }^{28}$ intended to reduce the risk of fluorosis by using a lower $F$ concentration toothpaste under 6 years of age ${ }^{29}$. It has been widely acknowledged, nonetheless, that low $\mathrm{F}$ toothpastes are both, not effective in reducing caries ${ }^{9,30}$ and incapable of preventing fluorosis ${ }^{31}$.

Currently, national and international regulations specify the upper limit or a range for total $\mathrm{F}$ that a toothpaste must contain. However, the minimum concentration of TSF should be also incorporated to the regulations ${ }^{32}$. The reduction of the caries-active fraction (i.e. TSF), below the evidence-based threshold of 1,000 ppm $\mathrm{F}$ after aging (Figure 1), could compromise the anticaries potential of a fluoridated dentifrice ${ }^{8,9}$. Hence, toothpaste \#4 that exhibited an important reduction of TSF ( $630 \mathrm{ppm} \mathrm{F}$ ), may well be ineffective against caries. Toothpastes \#16 and \#27 had a decrease in the This article is protected by copyright. All rights reserved 
soluble fraction of $F$, with an important increase in $\mathrm{InF}$, but they might remain active since TSF was slightly below 1,000 ppm F. Most toothpastes had an appropriate combination of the $F$ salt and the abrasive (MFP/calcium-based abrasive or $\mathrm{NaF} /$ silica-based abrasive), except for products \#16 and \#27. It is likely that the problem in the formulation may have resulted in a high InF fraction in the fresh condition. Product \#16 is fabricated with both F salts (MFP and also NaF) and a calcium-based abrasive. Thus, while MFP would prevent InF formation, NaF can react and form the compound. Likewise, product \#27 has NaF and silica/calcium-based abrasive in its formulation. It is reasonable that the high InF concentration is due to the reaction between $\mathrm{NaF}$ and the calcium-based abrasive. Inside the tube, $\mathrm{NaF}$ is transformed to its ionic form ( $\mathrm{F}-)$, which in turn can react with $\mathrm{Ca}^{++}$from the abrasive, forming caries-inactive and insoluble $\mathrm{CaF}_{2}$. Besides the inappropriate formulation of product \#27, it was marketed as a low- $F$ toothpaste intended for children (450 ppm F declared in the package). The TF content, however, was about $1,400 \mathrm{ppm} F$ and TSF was about 900 ppm after one year of storage. Discrepancies, like these must serve as an alert for national health systems. Regulatory entities in the countries should incorporate technical capacities to systematically monitor imported or nationally-manufactured products. Toothpastes \#28 and \#30 formed a high amount of InF, which reduced even more the originally low $\mathrm{F}$ concentration of about $450 \mathrm{ppm} F$, to a very low $F$ concentration of about $250 \mathrm{ppm} F$. Importantly, the European Academy of Paediatric Dentistry (EAPD) recommends low-F dentifrices in children between 6 months and 2 years old ${ }^{33}$. Thus, the very low TSF concentrations found in dentifrices \#28 and \#30 could make these products ineffective against caries. Toothpastes in children are intended to be used in small amounts and for that reason they could last longer at home than adult's toothpastes. If that were the case, optimal TSF levels must be ensured, so active $F$ is available during longer storage periods.

Consistent with other similar studies ${ }^{19,34}$, we decided to use one year as a reasonable time to experimentally age a toothpaste and to evaluate its $F$ stability. This time frame is a realistic maximal storage time for a toothpaste before it is sold, as most of these products are generally purchased a few weeks after being placed in the shelves of the stores. We are aware, nonetheless, that the fabrication date for a toothpaste placed in a shelf before being purchased may be highly variable. This issue is deepened below. The issue of the storage temperature is not easy to control and may This article is protected by copyright. All rights reserved 
represent an important source of variability across the commercial products. We chose to store at $22^{\circ} \mathrm{C}$, as this may be a realistic temperature inside a supermarket or drugstore, where temperature is usually maintained through air conditioning systems, at least during the day.

The Chilean regulation demands that toothpastes contain the expiration date in the labeling ${ }^{27}$, but not the fabrication date. We found that most toothpastes declared the expiration date (Table 1). However, only 3 out of 30 samples declared both the fabrication and expiration date. According to ISO, Chilean, Brazilian, American and European organizations ${ }^{18,35}$, fluoridated toothpastes are cosmetics products and they should not be sold after three years from being produced. However, when it was possible to match both dates, we found that the valid period for use, according to the manufacturer, was two years instead of three, as the regulation states. Due to these inconsistences ( 3 or 2 years), we avoided speculative estimates on the fabrication date when it was not explicitly declared (27 out of 30 samples). After one year of storage, 19 out of 30 toothpastes (63\%) were still within their valid period, according to the declared expiration date on the label. Some toothpastes (37\%) had at least one tube that expired during the storage period and we found that it varied between one month to almost a year after expiration date (product \#1, \#5, \#11, \#12 and \#28 between 9 -11 months after expiration; product\#30 between 6-9 months after expiration; products \#6, \#9, \#16 and \#19 between 3-5 months after expiration and product \#10, 1 month after expiration). Yet, among the expired toothpastes, only \#16 and \#28 showed a significant increase in InF (Fig. 1). The latter may be likely related to the MFP/calcium based abrasive composition, which reduced TSF after storage.

One of the reasons that led us to conduct this aging study is the fact that MFP/calcium based abrasive formulations are extensively used in developing countries $^{3,19,22,23}$, with reported TSF lack of chemical stability ${ }^{18,19}$. MFP/calcium may be considered a low-cost option for toothpaste manufacturing, because calciumbased abrasives are of lower cost than silica, which allows better access to these Fcontaining products by disadvantaged populations. In dentifrices that use silica as the only abrasive in the formulation, all $F$ will be found as soluble ${ }^{23}$. In our study, most of the toothpastes with an important reduction in TSF were MFP-formulated This article is protected by copyright. All rights reserved 
combined with calcium-based abrasive ( 4 of out 5 products). Although $F$ is covalently bound MFP-based toothpastes, the MFP molecule is not totally stable and hydrolysis inside the tube over time may occur ${ }^{14}$. This chemical change leads to a reduction in the levels of TSF by the formation of InF with the Ca from the abrasive $\mathrm{e}^{18,19,22,36}$.

It is of importance to mention that not all the formulations containing MFP/calcium showed a reduction in the TSF concentration. For example, toothpastes \#5 (all tubes expired), "\#10 (one tube expired and others with two months before expiration date) and \#19 (all tubes expired) were all MFP/carbonate-formulated. After aging for one year at room temperature, all these products were relatively stable exhibiting TSF in higher concentrations than $1,000 \mathrm{ppm} F$. Other studies suggest that TSF is maintained above $1,000 \mathrm{ppm} \mathrm{F}$ in MPF/calcium-based abrasive toothpastes during the first year after manufacturing ${ }^{24}$ and the reduction in TSF occurs when the product nears the expiration date ${ }^{18}$. Thus, MFP allows compatible formulations using calciumbased abrasive ${ }^{5}$, so this formulation is appropriate and can still be recommended. Yet, dental practitioners must be aware that the expected anticaries effect of these products may be compromised if exposed to high temperatures $\left(>28.9^{\circ} \mathrm{C}\right)^{19}$ or long storage periods ${ }^{18}$.

TSF content should be continuously verified and monitored in toothpastes manufactured and sold in specific countries or areas, as other reasons can affect $F$ stability in toothpastes. In fact, differences in $F$ stability over time among the different commercial products may arise from specific local conditions in the production with inadequate quality control, use of cheaper ingredients, weak regulations, problems in the distribution, slow turnover resulting in sales near or beyond the expiration date and high storage temperatures ${ }^{26}$. For all these reasons, optimal quality control on manufacturing and distribution is mandatory and requires technical capacity and strong national regulations. Commercial products should comply with minimum labelling and packaging requirements, such as ISO Standard $11609^{26,35}$. It is relevant that manufacturers clearly label the expiration date in the tube, so consumers can be informed about the quality of the product to achieve the expected effect on caries.

In summary, our data indicate that consumers in Chile can be confident that most of the toothpastes being sold in the country are within the valid usable period. After one This article is protected by copyright. All rights reserved 
year of storage, the majority of the toothpastes evaluated had similar TSF to the initial declared and measured values without any relevant degradation during the evaluation time, with only few exceptions. The reduction of TSF was mainly due to an inadequate $\mathrm{F}$ salt/abrasive formulation or to MFP hydrolysis inside the tube during prolonged storage. Active soluble $\mathrm{F}$ concentration in commercial dentifrices must be routinely monitored and regulated to guarantee the expected caries-preventive effect.

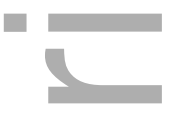

\section{Why this paper is important to paediatric dentists.}

- Besides the analyses included in the article, this study describes relevant aspects about toothpaste composition that every clinician must be aware of. Discussions on the availability of $\mathrm{F}$ generate important knowledge, so dentists can provide informed recommendations to patients and their parents.

- Despite regulations and quality control, some few products may have important reductions in active $F$ upon storage. Therefore, information on $F$ stability upon storage is relevant to understand a potential loss of efficacy of toothpastes.

- Clinicians must be careful in recommending products adequately formulated and in providing information on how to read labels to avoid using products beyond their expiration date, particularly those formulated with MFP. Moreover, concepts on the evidence-based minimal $\mathrm{F}$ concentration of $1,000 \mathrm{ppm}$ need to be reemphasized.

\section{References}

1 Bratthall D, Hansel-Petersson G, Sundberg $H$. Reasons for the caries decline: what do the experts believe? Eur J Oral Sci. 1996; 104: 416-422; discussion 423$425,430-432$.

2 Marthaler TM. Changes in dental caries 1953-2003. Caries Res. 2004; 38: 173-181.

3 Cury JA, Tenuta LM, Ribeiro CC, Paes Leme AF. The importance of fluoride dentifrices to the current dental caries prevalence in Brazil. Braz Dent J. 2004; 15: 167-174.

This article is protected by copyright. All rights reserved 
4 Fejerskov O, Cury JA, Tenuta LM, Marinho VC. Fluorides in caries control. In: Fejerskov O, Nyvad B, Kidd E, eds. Dental Caries: The Disease and Its Clinical Management. Oxford: Wiley Blackwell 2015:245-276.

5 Cury JA, Tenuta LM. Evidence-based recommendation on toothpaste use. Braz Oral Res. 2014; 28 Spec No: 1-7.

6 Marinho VC, Higgins JP, Sheiham A, Logan S. Fluoride toothpastes for preventing dental caries in children and adolescents. Cochrane Database Syst Rev. 2003: CD002278.

7 Kay $E$, Locker D. A systematic review of the effectiveness of health promotion aimed at improving oral health. Community Dent Health. 1998; 15: 132-144.

8 dos Santos AP, Nadanovsky P, de Oliveira BH. A systematic review and metaanalysis of the effects of fluoride toothpastes on the prevention of dental caries in the primary dentition of preschool children. Community Dent Oral Epidemiol. 2013; 41: $1-12$.

9 Walsh T, Worthington HV, Glenny AM, Appelbe P, Marinho VC, Shi X. Fluoride toothpastes of different concentrations for preventing dental caries in children and adolescents. Cochrane Database Syst Rev. 2010: CD007868.

10 Wong MC, Clarkson J, Glenny AM, Lo EC, Marinho VC, Tsang BW et al. Cochrane reviews on the benefits/risks of fluoride toothpastes. J Dent Res. 2011; 90: 573-579.

11 Ellwood RP, Cury JA. How much toothpaste should a child under the age of 6 years use? Eur Arch Paediatr Dent. 2009; 10: 168-174.

12 Falcao A, Tenuta LM, Cury JA. Fluoride gastrointestinal absorption from Na2FPO3/CaCO3- and NaF/SiO2-based toothpastes. Caries Research. 2013; 47: 226233.

13 Tenuta LM, Cury JA. Fluoride: its role in dentistry. Braz Oral Res. 2010; 24 Suppl 1: 9-17.

14 Tenuta LM, Cury JA. Laboratory and human studies to estimate anticaries efficacy of fluoride toothpastes. Monogr Oral Sci. 2013; 23: 108-124.

15 ten Cate JM. Contemporary perspective on the use of fluoride products in caries prevention. Br Dent J. 2013; 214: 161-167.

16 Cury J, Tenuta L. Enamel remineralization: controlling the caries disease or treating early caries lesions? Braz Oral Res. 2009; 23: 23-30.

This article is protected by copyright. All rights reserved 
17 Lippert F. An introduction to toothpaste - its purpose, history and ingredients. Monogr Oral Sci. 2013; 23: 1-14.

18 Cury JA, Viera ED, Tenuta LM, Romao DA, Tabchoury CP, Nobrega DF et al. [Fluoride concentration in most sold MFP/CaCO3- based Brazilian toothpastes at the expiration time]. Rev Assoc Paul Cir Dent. 2015; 69: 248-251.

19 Conde NC, Rebelo MA, Cury JA. Evaluation of the fluoride stability of dentifrices sold in Manaus, AM, Brazil. Pesqui Odontol Bras. 2003; 17: 247-253.

20 Giacaman RA, Carrera CA, Muñoz-Sandoval C, Fernandez C, Cury JA. Fluoride content in toothpastes commercialized for children in Chile and discussion on professional recommendations of use. Int J Paediatr Dent. 2013; 23: 77-83.

21 Carrera CA, Giacaman RA, Munoz-Sandoval C, Cury JA. Total and soluble fluoride content in commercial dentifrices in Chile. Acta odontologica Scandinavica. 2012; 70: 583-588.

22 Cury JA, Oliveira MJ, Martins CC, Tenuta LM, Paiva SM. Available fluoride in toothpastes used by Brazilian children. Braz Dent J. 2010; 21: 396-400.

23 Ricomini Filho AP, Tenuta LM, Fernandes FS, Calvo AF, Kusano SC, Cury JA. Fluoride concentration in the top-selling Brazilian toothpastes purchased at different regions. Braz Dent J. 2012; 23: 45-48.

24 Benzian $H$, Holmgren C, Helderman W. Efficacy of fluoride toothpaste over time. Braz Dent J. 2012; 23: 311-314; author reply 312-314.

25 van Loveren C, Moorer WR, Buijs MJ, van Palenstein Helderman WH. Total and free fluoride in toothpastes from some non-established market economy countries. Caries Res. 2005; 39: 224-230.

26 Benzian $H$, Holmgren C, Buijs $M$, van Loveren $C$, van der Weijden F, van Palenstein Helderman W. Total and free available fluoride in toothpastes in Brunei, Cambodia, Laos, the Netherlands and Suriname. International dental journal. 2012; 62: 213-221.

27 MINSAL. [Resolución exenta N784 "Uso de Fluoruros en la Prevencion Odontologica"]. Available at: https://odontopediatria.cl/wpcontent/uploads/2015/08/nueva_norma_pastas_dentales.pdf. (Last accessed, Sept 12th, 2016).

. Ministerio de Salud de Chile. 2015.

28 MINSAL. Regulation for the Use of Fluoride in Preventive Dentistry. Health Ministry of Chile. 2008:27-32.

This article is protected by copyright. All rights reserved 
29 Horowitz HS. The need for toothpastes with lower than conventional fluoride concentrations for preschool-aged children. Journal of public health dentistry. 1992;

52: 216-221.

30 dos Santos AP, Nadanovsky P, de Oliveira BH. A systematic review and metaanalysis of the effects of fluoride toothpastes on the prevention of dental caries in the primary dentition of preschool children.Evid Based Dent. 2014; 1: 5. Evid Based Dent. 2014; 15: 67.

31 Santos AP, Oliveira BH, Nadanovsky P. Effects of low and standard fluoride toothpastes on caries and fluorosis: systematic review and meta-analysis. Caries Res. 2013; 47: 382-390.

32 Cury JA, Caldarelli PG, Tenuta LM. Necessity to review the Brazilian regulation about fluoride toothpastes. Revista de saude publica. 2015; 49.

33 EAPD. Guidelines on the use of fluoride in children: an EAPD policy document. Eur Arch Paediatr Dent. 2009; 10: 129-135.

34 Hashizume LN, Lima YB, Kawaguchi Y, Cury JA. Fluoride availability and stability of Japanese dentifrices. J Oral Sci. 2003; 45: 193-199.

35 ISO. Dentistry - Dentifrices - Requirements, test methods and marking. ISO 11609:2010.

Available

at: http://www.iso.org/iso/catalogue detail.htm?csnumber=38010. (Last accessed, Sept 12th, 2016). International Organization for Standardization. 2010.

36 de Freitas JF. Fluoride stability in toothpastes. Aust Dent J. 1984; 29: 30-35.

\section{Figure Legends}

Figure 1. Total soluble fluoride (TSF) and insoluble fluoride (InF) in fresh and aged toothpastes (mean of 3 tubes analyzed in duplicate) (Table 1). Bold black line highlights the anticaries effectiveness threshold of $1,000 \mathrm{ppm}$ F.

\section{Tables}

Table 1: Total $F$ and total soluble $F$ measured in fresh and aged toothpastes $(n=3$ tubes analyzed in duplicate; mean \pm SD). 


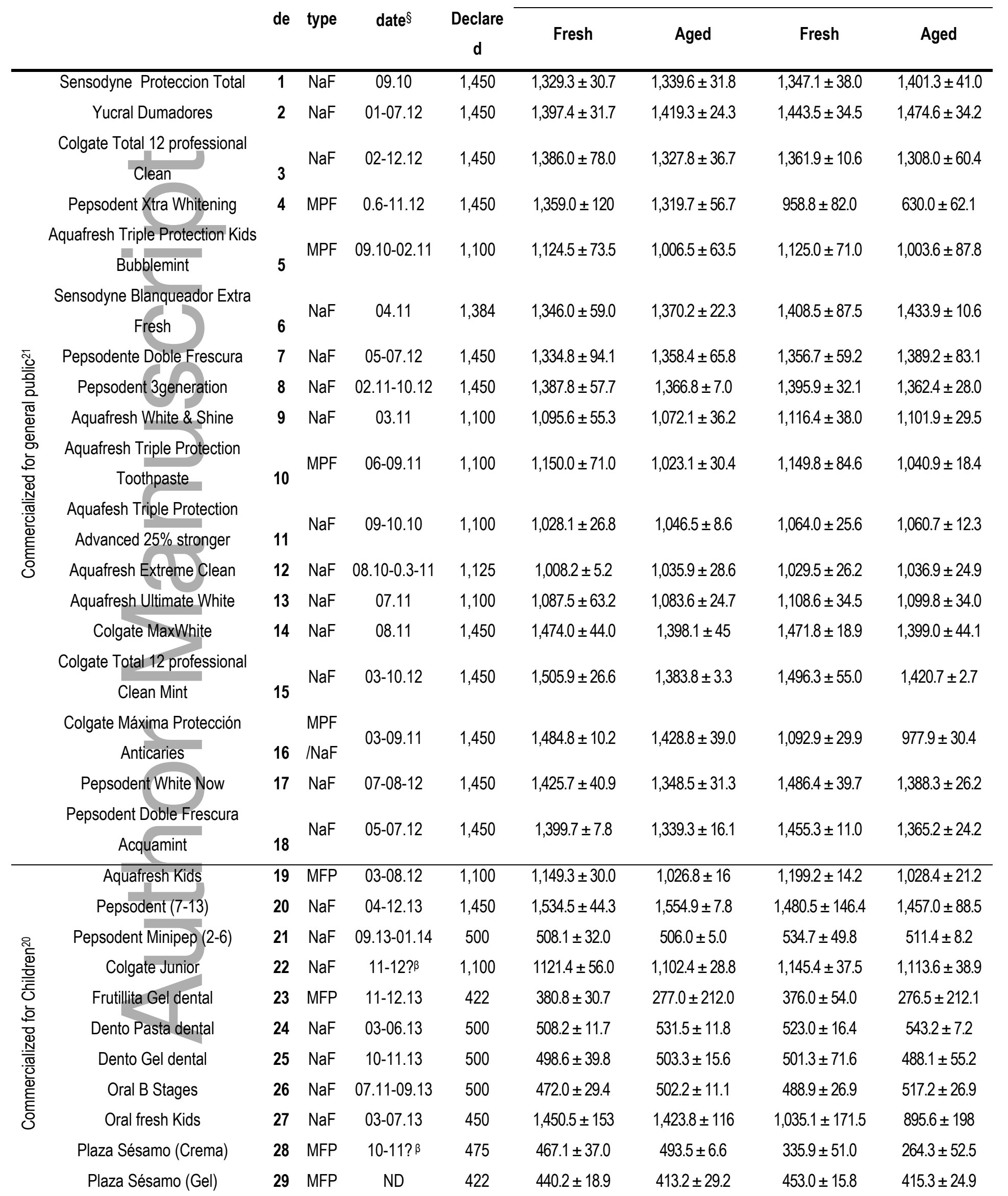

This article is protected by copyright. All rights reserved 


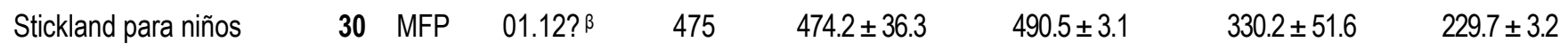

NaF: sodium fluoride; MPF: monofluorphophate

$\S$ Expiration date is described as month.year or month-month.year when different lots had different expirations dates (range).

$\beta$ the date was not clear in the label.

ND: not declared in the label.

Toothpastes commercialized for general public were analyzed in 07.10 (fresh) and 07.11 (aged)

Toothpastes commercialized for children were analyzed in 07.11 (fresh) and 08.12 (aged)

-
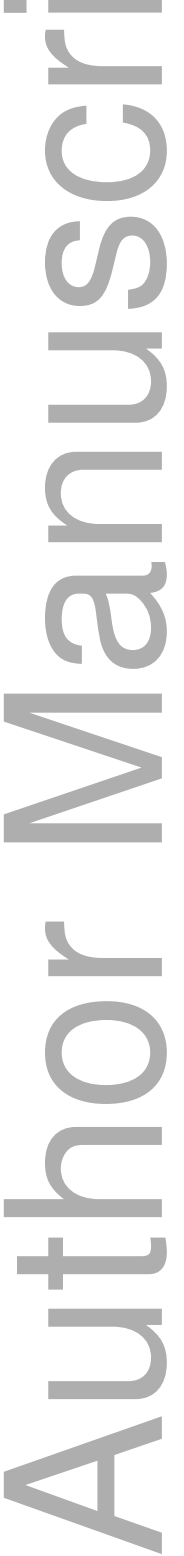


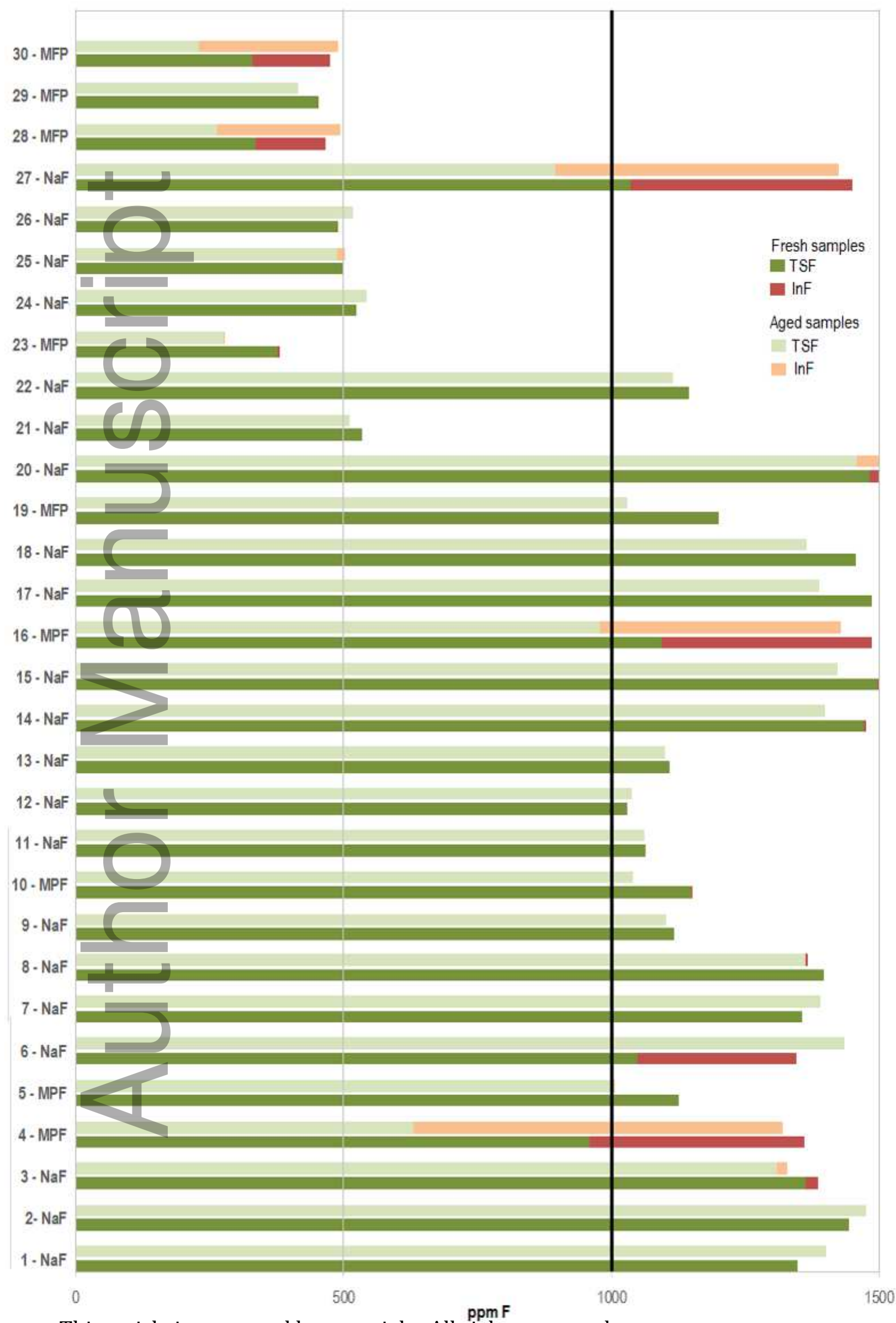

This article is protected by copyright. All rights reserved 